Check for updates

Cite this: RSC Adv., 2020, 10, 7927

\title{
Aerobic photooxidative hydroxylation of boronic acids catalyzed by anthraquinone-containing polymeric photosensitizer $\dagger$
}

\author{
Yang Chen, ${ }^{a}$ Jianhua $\mathrm{Hu}^{* a}$ and Aishun Ding (D) *b
}

We report herein the synthesis of a polymeric photosensitizer and its application in aerobic photooxidative hydroxylation of boronic acids. The polymeric photosensitizer was synthesized by the condensation of anthraquinone-2-carbonyl chloride ( $\mathrm{AQ}-2-\mathrm{COCl}$ ) with poly (2-hydroxyethyl methacrylate) (PHEMA). The photo-oxidative hydroxylation of boronic acids using anthraquinone-containing-poly (2-hydroxyethyl methacrylate) (AQ-PHEMA) was then explored and shown to exhibit high efficiency and broad scope. Moreover, AQ-PHEMA could be easily recovered and reused for more than 20 times without significant loss of the catalytic activity.

Received 8th January 2020

Accepted 17th February 2020

DOI: $10.1039 / \mathrm{dOra00176g}$

rsc.li/rsc-advances

hydroxylation of boronic acids is another hot topic, which has received much attention in the past decade. ${ }^{29-32}$ In this transformation, the superoxide radical anion generated by single

Oxidative hydroxylation of boronic acids is one of the most important methods for the synthesis of phenols or alcohols. ${ }^{1-7}$ Strong oxidants such as ozone, ${ }^{8}$ high-valence halogen compounds, ${ }^{9-11}$ peroxides and $\mathrm{N}$-oxides ${ }^{12}$ are efficient reagents for such transformations (Scheme 1a). However, these methods generate large amounts of wastes detrimental to the environment. Oxygen in air is a green oxidant with environmentfriendly feature. The methods using oxygen have been well studied. ${ }^{13,14}$ Some $\mathrm{Ru},{ }^{15} \mathrm{Pd},{ }^{16} \mathrm{Fe},{ }^{17} \mathrm{Cu},{ }^{18-20}$ complexes have been reported to be effective catalysts in this reaction (Scheme $1 \mathrm{~b}$ ). However, the catalysts are expensive, hard to synthesis, and not environmentally friendly. The metal-free catalyst processes provide a promising alternative (Scheme $1 \mathrm{c})^{21}$ wherein good catalytic activity could be envisioned.

Visible light is an inexhaustible green energy. ${ }^{22-24}$ Photosensitizer-catalyzed transformations have shown very important applications in photochemistry. ${ }^{25-27}$ Numerous achievements have been reported in this field. For example, Guo group reported selective cleavage and formation of $\mathrm{C}_{\mathrm{sp}^{2}}-\mathrm{I}$ bond, using carefully-designed thioxanthone derivative. ${ }^{28}$ This was the first example of $\mathrm{C}_{\mathrm{sp}^{2}}-\mathrm{I}$ bond cleavage by means of photosensitizing, which highlights the potential of small molecular photosensitizer. Visible light photosensitizer-catalyzed oxidative

${ }^{a}$ State Key Laboratory of Molecular Engineering of Polymers, Department of Macromolecular Science, Fudan University, 2005 Songhu Road, Shanghai 200438, PR China. E-mail: hujh@fudan.edu.cn; Fax: +86-21-31242888; Tel: +86-21-55665280 ${ }^{b}$ Department of Chemistry, Fudan University, 2005 Songhu Road, Shanghai 200438, PR China. E-mail: shunzi0522@126.com; Fax: +86-21-31249190; Tel: +86-2131249190

$\uparrow$ Electronic supplementary information (ESI) available: Experimental procedures, and characterization data for all compounds. See DOI: 10.1039/d0ra00176g

Scheme 1 Oxidative hydroxylation of boronic acids with small molecular catalysts.

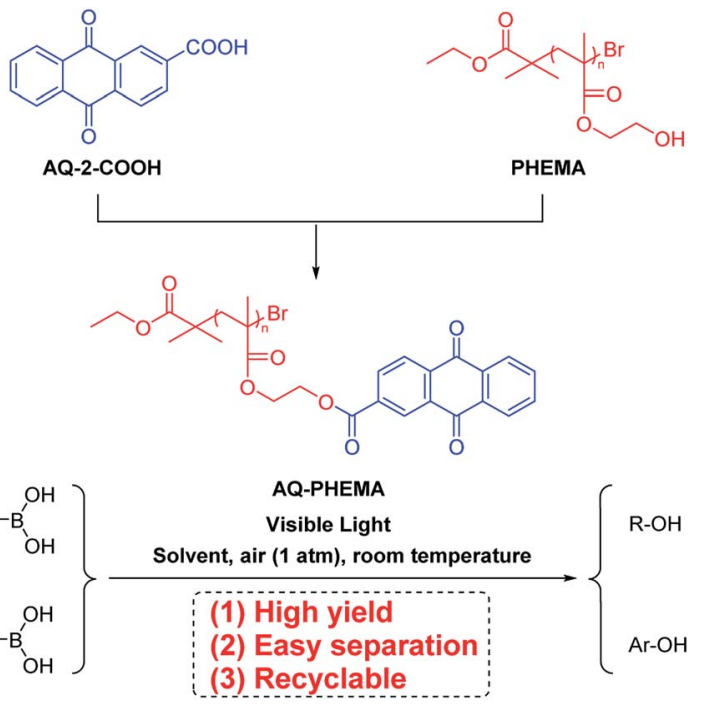

Scheme 2 The synthetic procedure of AQ-PHEMA and its application in photooxidative hydroxylation of boronic acids. 
electron transfer could coordinate with the boron atom, then the reaction undergoes rearrangement and hydrolysis to produce the final phenol or alcohol. ${ }^{33,34}$ Small molecule photosensitizers has the significant disadvantage as a homogenous catalyst, as they are difficult to be recycled or reused. With our continuous interest in the synthesis and application of PHEMA, ${ }^{35}$ we proposed to synthesize a novel macromolecular photocatalyst by introducing anthraquinone (AQ) group of anthraquinone-2-carboxylic acid $(\mathrm{AQ}-2-\mathrm{COOH})^{36-38}$ into polymeric chains of PHEMA (Scheme 2). This polymeric catalytic material can be easily recovered and reused after catalyzing photoreaction. Herein, we wish to report our recent research in aerobic oxidative hydroxylation of boronic acids employing AQ-PHEMA (for synthesis and characterization of AQ-PHEMA, see ESI $\dagger$ ) as catalyst.

\section{Results and discussion}

\section{Optimization and scope investigation}

In the beginning, (4-methoxyphenyl)boronic acid (1a) was chosen as the model substrate to optimize the AQ-PHEMA- catalyzed photooxidative hydroxylation of boronic acids. The initial attempt was carried out using $\mathrm{i}-\mathrm{Pr}_{2} \mathrm{NEt}$ as the electron donor, $\mathrm{CH}_{3} \mathrm{CN}$ as the solvent at rt under air atmosphere. An 86\% NMR yield of desired product 4-methoxyphenol (2a) was formed after irradiation under a purple LED for 35 hours (entry 1, Table 1). With this result in hand, a survey of solvents was carried out (entries 2-16, Table 1). Reactions in ether, toluene, or dichloromethane gave lower yield (entries 2-4, Table 1). While methyl tert-butyl ether (MTBE), acetone, $\mathrm{CH}_{3} \mathrm{NO}_{2}$, or THF resulted in slightly higher yield (entries 5-8, Table 1). When methyl acetate, EtOH or $\mathrm{CH}_{3} \mathrm{OH}$ was chosen as the solvent, the yield of $2 \mathbf{a}$ was remarkably increased (entries 9-11, Table 1). Reactions in propyl acetate or isopropyl acetate resulted in similar excellent yields (entries 12 and 13, Table 1). When ethyl acetate, dimethyl carbonate (DMC) or 1,4-dioxane was employed as the solvent, the NMR yield of 2 a was increased to $99 \%$ (entries 14-16, Table 1). Considering the reaction time, 1,4-dioxane was chosen as the optimal solvent. Notably, AQ-PHEMA is insoluble in all the above tested solvents and can only be dispersed in the solvent, so it can be

Table 1 Optimization of the reaction conditions ${ }^{a}$

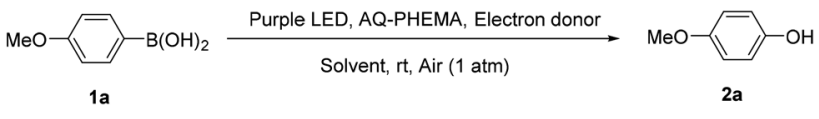

\begin{tabular}{|c|c|c|c|c|c|}
\hline Entry & Solvent & Catalyst (mol\%) & e-Donor (equiv.) & Time (h) & Yield $^{b}(\%)$ \\
\hline 1 & $\mathrm{CH}_{3} \mathrm{CN}$ & 5 & $\mathrm{i}-\mathrm{Pr}_{2} \mathrm{NEt}(2)$ & 35 & 86 \\
\hline 2 & $\mathrm{Et}_{2} \mathrm{O}$ & 5 & $\mathrm{i}-\mathrm{Pr}_{2} \mathrm{NEt}(2)$ & 48 & 34 \\
\hline 3 & Toluene & 5 & $\mathrm{i}-\mathrm{Pr}_{2} \mathrm{NEt}(2)$ & 48 & 46 \\
\hline 4 & DCM & 5 & i-Pr ${ }_{2} \mathrm{NEt}(2)$ & 48 & 51 \\
\hline 5 & MTBE & 5 & i- $\mathrm{Pr}_{2} \mathrm{NEt}(2)$ & 48 & 67 \\
\hline 6 & Acetone & 5 & $\mathrm{i}-\mathrm{Pr}_{2} \mathrm{NEt}(2)$ & 48 & 68 \\
\hline 7 & $\mathrm{CH}_{3} \mathrm{NO}_{2}$ & 5 & $\mathrm{i}-\mathrm{Pr}_{2} \mathrm{NEt}(2)$ & 37 & 74 \\
\hline 8 & THF & 5 & $\mathrm{i}-\mathrm{Pr}_{2} \mathrm{NEt}(2)$ & 42 & 78 \\
\hline 9 & Methyl acetate & 5 & $\mathrm{i}-\mathrm{Pr}_{2} \mathrm{NEt}(2)$ & 38 & 84 \\
\hline 10 & EtOH & 5 & i-Pr ${ }_{2} \mathrm{NEt}(2)$ & 33 & 89 \\
\hline 11 & $\mathrm{MeOH}$ & 5 & i-Pr ${ }_{2} \mathrm{NEt}(2)$ & 32 & 92 \\
\hline 12 & Propyl acetate & 5 & i-Pr ${ }_{2} \mathrm{NEt}(2)$ & 36 & 95 \\
\hline 13 & Ispropyl acetate & 5 & $\mathrm{i}-\mathrm{Pr}_{2} \mathrm{NEt}(2)$ & 36 & 96 \\
\hline 14 & Ethyl acetate & 5 & i-Pr ${ }_{2}$ NEt (2) & 29 & 99 \\
\hline 15 & DMC & 5 & i- $\operatorname{Pr}_{2} \mathrm{NEt}(2)$ & 34 & 99 \\
\hline 16 & 1,4-Dioxane & 5 & i-Pr ${ }_{2} \mathrm{NEt}(2)$ & 27 & 99 \\
\hline 17 & 1,4-Dioxane & 5 & $\mathrm{NH}_{3} \cdot \mathrm{H}_{2} \mathrm{O}(4 \mathrm{~mL})$ & 27 & $45(34)^{c}$ \\
\hline 18 & 1,4-Dioxane & 5 & DBU & 27 & 69 \\
\hline 19 & 1,4-Dioxane & 5 & Dicyclohexylamine & 27 & 82 \\
\hline 20 & 1,4-Dioxane & 5 & $\mathrm{NEt}_{3}$ & 27 & 84 \\
\hline 21 & 1,4-Dioxane & 5 & $\mathrm{i}-\mathrm{Pr}_{2} \mathrm{NEt}(1)$ & 27 & $81(14)^{c}$ \\
\hline 22 & 1,4-Dioxane & 3 & $\mathrm{i}-\mathrm{Pr}_{2} \mathrm{NEt}(2)$ & 27 & $99(97)^{d}$ \\
\hline 23 & 1,4-Dioxane & 1 & $\mathrm{i}-\mathrm{Pr}_{2} \mathrm{NEt}(2)$ & 27 & $83(11)^{c}$ \\
\hline 24 & 1,4-Dioxane & - & $\mathrm{i}-\mathrm{Pr}_{2} \mathrm{NEt}(2)$ & 27 & $11(89)^{c}$ \\
\hline $25^{e}$ & 1,4-Dioxane & 3 & $\mathrm{i}-\mathrm{Pr}_{2} \mathrm{NEt}(2)$ & 27 & $0(99)^{c}$ \\
\hline $26^{e, f}$ & 1,4-Dioxane & 3 & $\mathrm{i}-\mathrm{Pr}_{2} \mathrm{NEt}(2)$ & 27 & $0(99)^{c}$ \\
\hline $27^{g}$ & 1,4-Dioxane & 3 & i- $\operatorname{Pr}_{2} \mathrm{NEt}(2)$ & 12 & 99 \\
\hline $28^{h}$ & 1,4-Dioxane & - & $\mathrm{i}-\mathrm{Pr}_{2} \mathrm{NEt}(2)$ & 27 & $10(90)^{c}$ \\
\hline
\end{tabular}

${ }^{a}$ The reaction were carried out using $\mathbf{1 a}(1 \mathrm{mmol})$ in solvent $(5 \mathrm{~mL})$, irradiated by purple LED under air atmosphere at rt. (Based on AQ anchored on PHEMA, the mass of $5 \mathrm{~mol} \%$ AQ-PHEMA is $17 \mathrm{mg}$; the mass of $3 \mathrm{~mol} \%$ AQ-PHEMA is $10 \mathrm{mg}$; the mass of $1 \mathrm{~mol} \%$ AQ-PHEMA is $3 \mathrm{mg}$ ). ${ }^{b}$ Yield determined by ${ }^{1} \mathrm{H}$ NMR analysis using $\mathrm{CH}_{2} \mathrm{Br}_{2}(1 \mathrm{mmol})$ as internal standard. ${ }^{c}$ Recovered yield of $1 \mathrm{a}$ determined by ${ }^{1} \mathrm{H}$ NMR analysis using $\mathrm{CH}_{2} \mathrm{Br}_{2}(1 \mathrm{mmol})$ as internal standard. ${ }^{d}$ Isolated yield of 2a. ${ }^{e}$ The reaction was carried out without light. ${ }^{f}$ The reaction was carried out at $80{ }^{\circ} \mathrm{C} .{ }^{g}$ The reaction was carried out using $3 \mathrm{~mol} \% \mathrm{AQ}$ as catalyst. ${ }^{h}$ The reaction was carried out in the presence of 4 mg of PHEMA. 
easily recovered by simple filtration. Next, the screening of electron donors was carried out. Ammonia gave a poor yield and the DBU did not work very well (entries 17 and 18, Table 1). Secondary amine (dicyclohexylamine) and tertiary amine $\left(\mathrm{NEt}_{3}\right)$ gave decreased yields (entries 19 and 20, Table 1). Decreasing the amount of $\mathrm{i}-\mathrm{Pr}_{2} \mathrm{NEt}$ to 1 equivalent resulted in a decreased in yield (entry 21, Table 1). Next, optimization of catalyst loading were conducted (entries 22 and 23, Table 1). The results showed that $3 \mathrm{~mol} \%$ catalytic is suitable (entry 22, Table 1). Control experiments were also performed which demonstrated the necessity of both the catalyst and light (entries 24 and 25, Table 1). Furthermore, a reaction carried out at $80{ }^{\circ} \mathrm{C}$ without light did not lead to any conversion, eliminating the possibility of the thermal effect of the LED light (entry 26, Table 1). Next, the oxidation using AQ as catalyst was conducted as comparasion. The reaction was completed in 12 hours in an excellent yield (entry 27, Table 1). However, AQ was difficult to recover in 1,4-dioxane. Finally, the oxidation using PHEMA as catalyst was investigated and no reaction took place (entry 28, Table 1 ). The above results clearly demonstrated that AQ was the key catalyst in this transformation. We also tried other different wavelengths for LED lights (Table S1†). The results showed that reactions at other wavelengths were similar to background reactions and purple LED is the only working light source in this reaction. Thus, Condition A ( 3 mol\% of AQ-PHEMA, i- $\operatorname{Pr}_{2}$ NEt ( 2 equiv.), 1,4-dioxane, purple LED, air (1 atm), and room temperature) was considered as the optimized conditions for further studies.

With the optimal conditions in hand, we explored the scope of this oxidative hydroxylation (Table 2). Firstly, the electronic effect of the arylboronic acids was examined. Substrates with strong electron donating group, like ortho-, meta- and para-methoxy, showed nice reactivity with excellent yields (2a-2c). Para-aminophenol was also obtained in an excellent yield (2d). Weak electron donating group such as ortho-, meta- and para-methyl (2e-2g), ethyl (2h), and phenyl (2i) were also conducted and generated in similar excellent yields. Phenol could be obtained from phenylboronic acid with an excellent yield ( $2 \mathbf{j})$. Nice reactivity was also acquired with halogen bearing arylboronic acids (2k-2n). Substrates with strong electron withdrawing groups (EWGs), including nitro (2o), ortho-, meta- and para-(trifluoromethyl) (2p-2r), and ortho-, meta- and para-nitrile (2s-2u) also showed high reactivities as well as excellent yields. Reactions with other electron withdrawing groups, like formyl (2v), acetyl (2w), methoxy carbonyl (2x) and carboxyl (2y) were also showed excellent reactivities in excellent yields. Further naphthyl groups were employed, and both $\alpha$ - and $\beta$-naphthol $(2 z$ and 2aa) could obtain excellent yields. Next, we tested some heteroaromatic boronic acids. Unfortunately, the resulting reaction mixtures were complicated (2ab-2af).

Furthermore, some alkyl and alkenyl boronic acid, as well as aryl boronic acid esters were studied (Table 3). Under condition A, cyclohexylboronic acid (3a) gave a good yield of cyclohexanol (4a). Alkenyl boronic (3b and 3c) gave similar good yields of $4 \mathbf{b}$ and 4c. In this case, aldehyde products were formed. Aryl
Table 2 The oxidative hydroxylation of arylboronic acid under condition $\mathrm{A}^{a} \mathrm{a}$
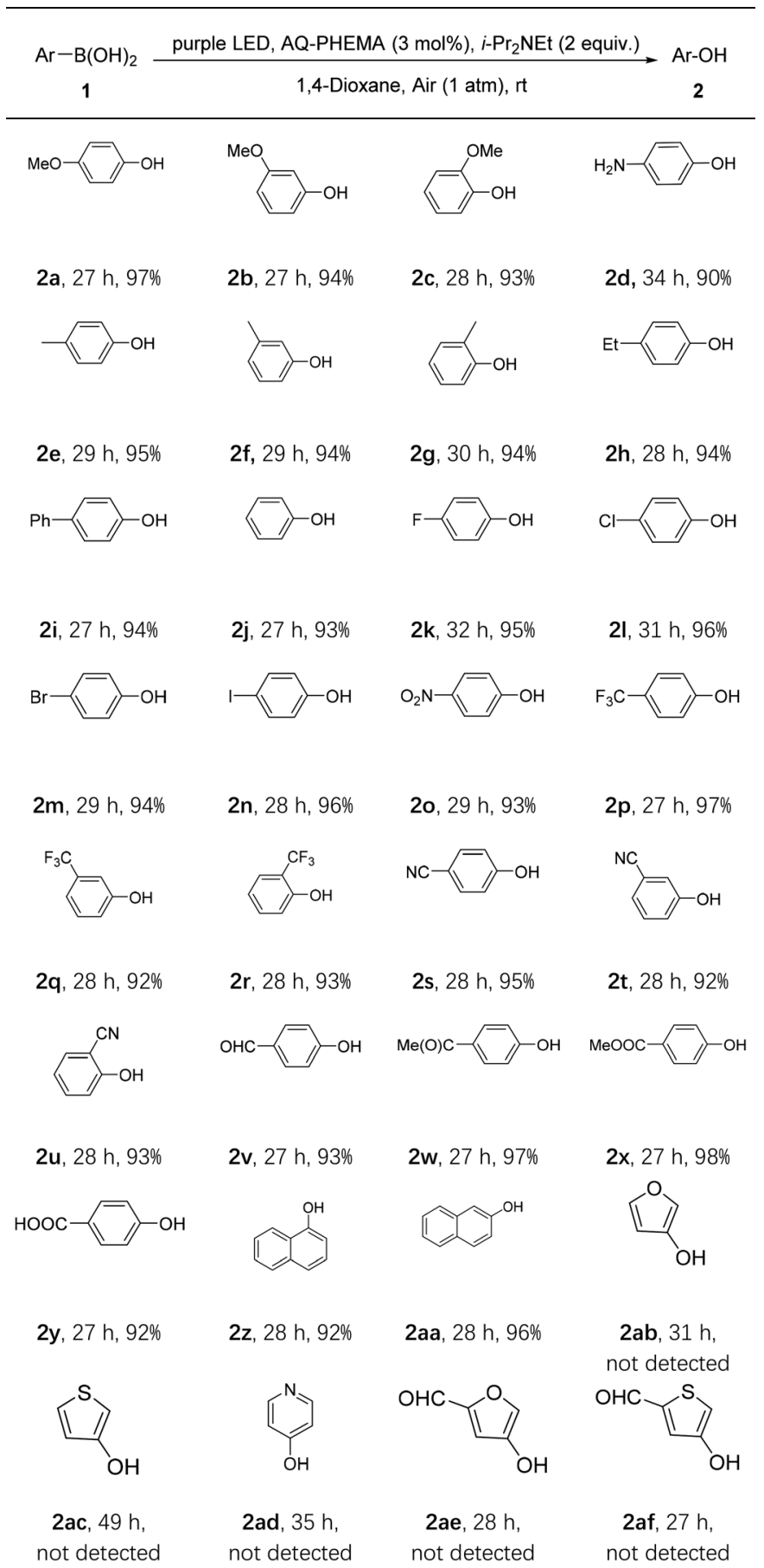

${ }^{a}$ All reactions were carried out using 1 ( $1 \mathrm{mmol}$ ), AQ-PHEMA ( 3 mol\%), i- $\operatorname{Pr}_{2} \operatorname{NEt}$ (2 equiv.), in 1,4-dioxane ( $5 \mathrm{~mL}$ ) irradiated by a purple LED light at rt under air atmosphere. Isolated yield was reported.

boronic acid ester (3d and 3e) also gave excellent yields of phenol (2j) and phenylmethanol (4e). The above results showed high functional group tolerance and very good substrate scope. Finally, a gram-scale reaction using $\mathbf{1 x}$ under condition A afforded 2x in 96\% (Scheme 3), demonstrating the scalability and practicality of the current reaction. 
Table 3 The oxidative hydroxylation of $3 a-e$ under condition $\mathrm{A}^{a} \mathrm{a}$

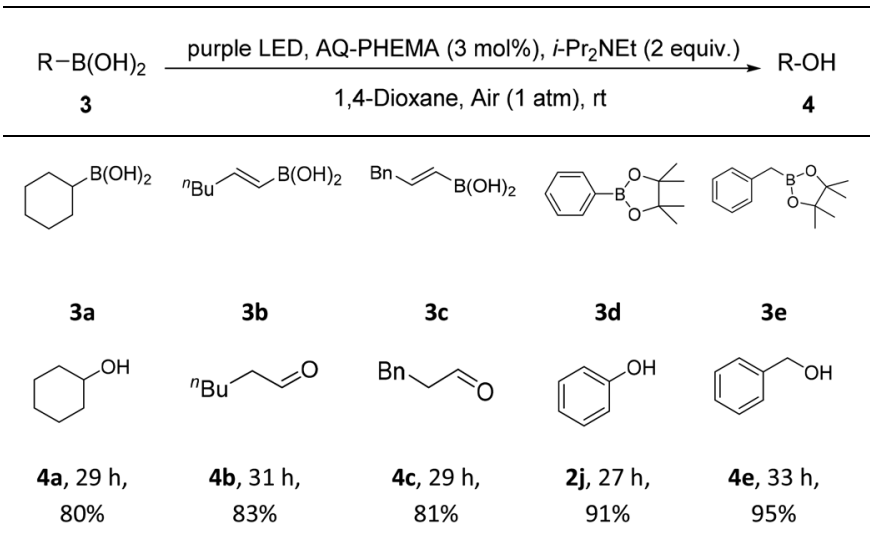

${ }^{a}$ All reactions were carried out using 1 ( $\left.1 \mathrm{mmol}\right)$, AQ-PHEMA ( $\left.3 \mathrm{~mol} \%\right)$, i- $\mathrm{Pr}_{2} \mathrm{NEt}$ ( 2 equiv.), in 1,4-dioxane ( $5 \mathrm{~mL}$ ) irradiated by a purple LED light at $\mathrm{rt}$ under air atomsphere. Isolated yield was reported.

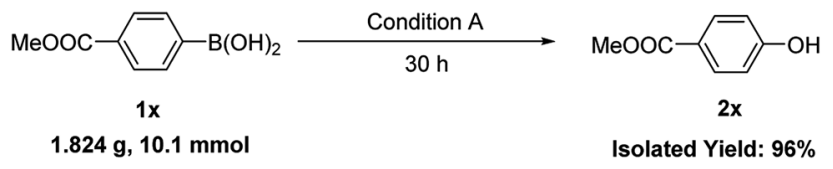

Scheme 3 Gram scale reaction.

\section{Recycling experiments}

To investigate the recyclability of AQ-PHEMA in photooxidative hydroxylation of boronic acids. 4-Methoxycarbonylbenzeneboronic acid (1x) was selected as the model substrate for the AQPHEMA recycling experiments under condition A. 1x was completely consumed after 27 hours and the NMR yield of the product 4-methoxycarbonylphenol (2x) was 99\% in the first cycle of the photocayalytic reaction. After the first cycle, the catalyst AQPHEMA could be easily separated and recovered by simple filtration and directly used for the next cycle under the same procedure. Finally, we found that AQ-PHEMA could be reused more than 20 times without significant loss of the catalytic activity (Fig. 1).

After the recycling experiments (21 cycles), the recovered AQPHEMA was characterized by ${ }^{1} \mathrm{H}$ NMR and GPC. As shown in Fig. 2, no significant changes were observed on the ${ }^{1} \mathrm{H}$ NMR spectra compared to the original AQ-PHEMA. The molecular weight $M_{\mathrm{n}, \mathrm{GPC}}$

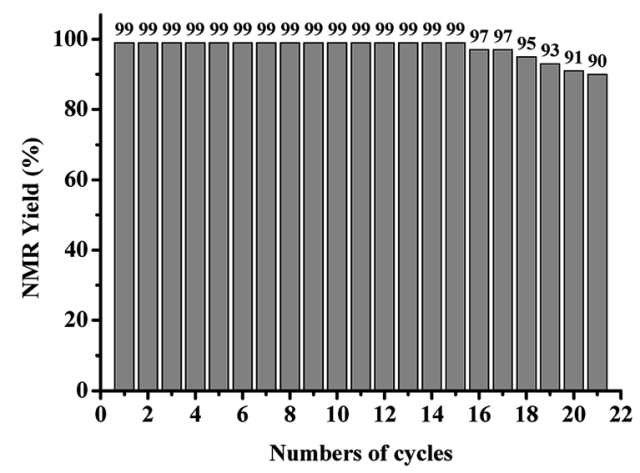

Fig. 1 Recycling experiments of the photocatalytic reaction of $1 \mathrm{x}$.

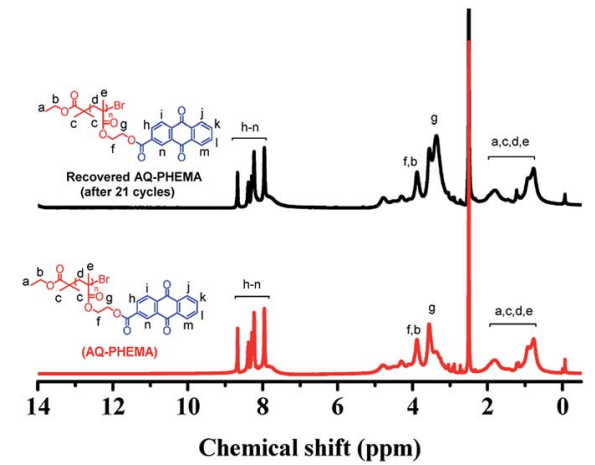

Fig. $2{ }^{1} \mathrm{H}$ NMR spectra for the recovered AQ-PHEMA (after 21 cycles) and the original AQ-PHEMA in $d_{6}$-DMSO.

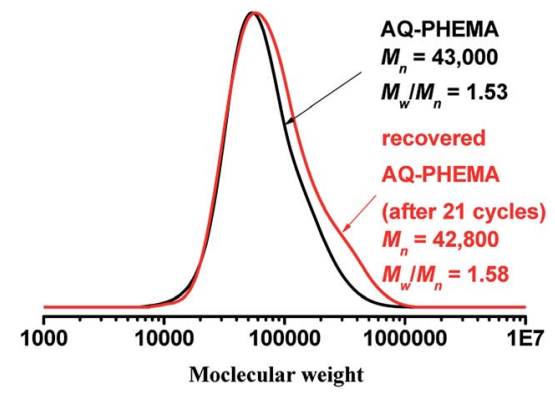

Fig. 3 The GPC traces of the original AQ-PHEMA and the recovered AQ-PHEMA (after 21 cycles).

and molecular distribution $M_{\mathrm{w}} / M_{\mathrm{n}}$ of the recovered AQ-PHEMA (after 21 cycles) were very close to the original AQ-PHEMA (Fig. 3). These results clearly indicated that the structure of AQPHEMA did not change during the whole catalytic procedure.

\section{Mechanism studies}

To gain insights into the reaction mechanism, some control experiments were carried out (Scheme 4). When 2 equivalents of 9,10-dimethylanthracene (5) was added to the reaction system as an organic singlet oxygen quencher, ${ }^{39}$ severe inhibition was observed. Bis((dibutylcarbamothioyl)th-io) nickel(II) (6) was also tried as an inorganic singlet oxygen quencher. ${ }^{40}$ Similarly, severe inhibition was also observed with 2 equivalents of 6 (Scheme $4 \mathrm{a}$ ). $N$-tert-Butyl-1-phenylmethanimine oxide (7), a superoxide radical anion quencher, ${ }^{\mathbf{4 1}-43}$ was used, the reaction was efficiently inhibited when 2 equivalents of 7 was added (Scheme $4 \mathrm{~b}$ ). The results above suggested that both singlet oxygen and superoxide radical anion were likely involved in this reaction. Cyclic voltammogram of AQ-PHEMA was also recorded under irradiation. (see Fig. $\mathrm{S} 2 \dagger$ ) The redox potential validated the single electron oxidation of AQ-PHEMA by oxygen might occur under irradiation.

\section{Proposed mechanism}

Based on the above control experiments and literature reports, ${ }^{36-38,44-48}$ a possible reaction mechanism was described as shown in Fig. 4. Firstly, AQ-PHEMA was excited under photo 


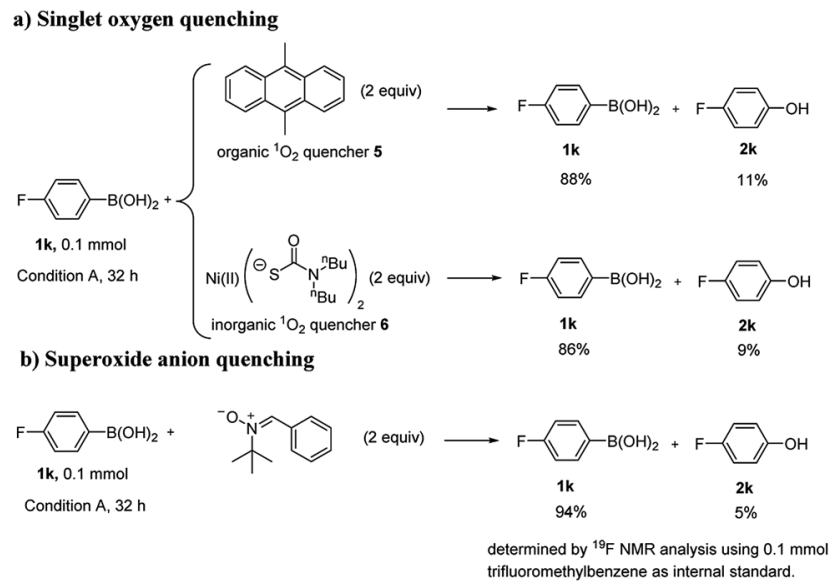

Scheme 4 Mechanism studies.

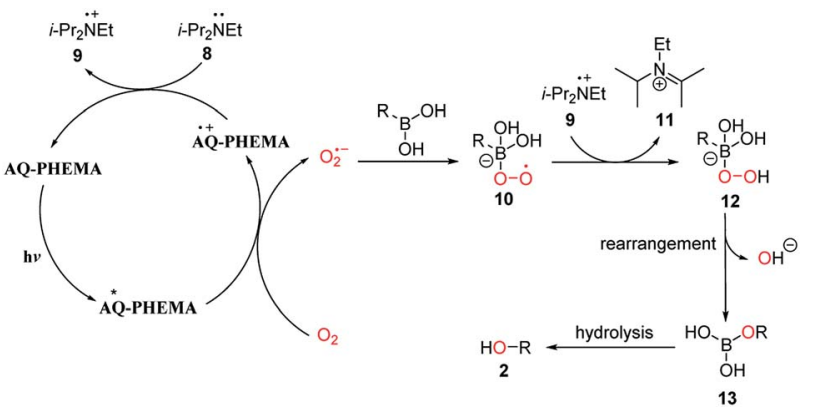

Fig. 4 Proposed mechanism.

irradiation reacts with molecular oxygen via SET to generate the superoxide radical anion, which further reacted with the boronic acid to form intermediate 10. Intermediate $\mathbf{1 0}$ then abstracts a hydrogen atom from 9 to generate intermediate $\mathbf{1 2}$. $\mathbf{1 2}$ then undergoes rearrangement to form $\mathbf{1 3}$ and then hydrolysis to produce the final product 2 .

\section{Conclusions}

In conclusion, we developed a photochemically aerobic photooxidation hydroxylation of boronic acids employing the polymeric photosensitizer AQ-PHEMA as the catalyst. The reaction is excellent yielding and highly efficient and demonstrates broad functional group tolerance. The AQ-PHEMA catalyst could be easily recovered by simple filtration and reused for more than 20 times. The excellent photocatalytic property, easy separation, and recyclability meet the requirements of green chemistry and showed great practical potentials.

\section{Conflicts of interest}

There are no conflicts to declare.

\section{Acknowledgements}

We greatly acknowledge the financial support from Shanghai Scientific and Technological Innovation Project (18YF1428800).

\section{References}

1 A. Ding, Y. Zhang, Y. Chen, R. Rios, J. Hu and H. Guo, Tetrahedron Lett., 2019, 60, 660-663.

2 H. Kotoucova, I. Strnadova, M. Kovandova, J. Chudoba, H. Dvorakova and R. Cibulka, Org. Biomol. Chem., 2014, 12, 2137-2142.

3 W. Ding, J.-R. Chen, Y.-Q. Zou, S.-W. Duan, L.-Q. Lu and W.-J. Xiao, Org. Chem. Front., 2014, 1, 151-154.

4 H. L. Qi, D. S. Chen, J. S. Ye and J. M. Huang, J. Org. Chem., 2013, 78, 7482-7487.

5 H. Jiang, L. Lykke, S. U. Pedersen, W. J. Xiao and K. A. Jorgensen, Chem. Commun., 2012, 48, 7203-7205.

6 K. Hosoi, Y. Kuriyama, S. Inagi and T. Fuchigami, Chem. Commun., 2010, 46, 1284-1286.

7 E. Kianmehr, M. Yahyaee and K. Tabatabai, Tetrahedron Lett., 2007, 48, 2713-2715.

8 Y. K. Bommegowda, N. Mallesha, A. C. Vinayaka and M. P. Sadashiva, Chem. Lett., 2016, 45, 268-270.

9 J. Gatenyo, I. Vints and S. Rozen, Chem. Commun., 2013, 49, 7379-7381.

10 U. Bora and A. Gogoi, Synlett, 2012, 23, 1079-1081.

11 P. Gogoi, P. Bezboruah, J. Gogoi and R. C. Boruah, Eur. J. Org. Chem., 2013, 2013, 7291-7294.

12 R. W. Chen Zhu and J. R. Falck, Org. Lett., 2012, 14, 34943497.

13 W. Yin, X. Pan, W. Leng, J. Chen and H. He, Green Chem., 2019, 21, 4614-4618.

14 W. Z. Weng, H. Liang and B. Zhang, Org. Lett., 2018, 20, 4979-4983.

15 N. Gogoi, P. K. Gogoi, G. Borah and U. Bora, Tetrahedron Lett., 2016, 57, 4050-4052.

16 A. D. Chowdhury, S. M. Mobin, S. Mukherjee, S. Bhaduri and G. K. Lahiri, Eur. J. Inorg. Chem., 2011, 2011, 3232-3239.

17 S. Chatterjee and T. K. Paine, Inorg. Chem., 2015, 54, 97279732.

18 H. Yang, Y. Li, M. Jiang, J. Wang and H. Fu, Chem.-Eur. J., 2011, 17, 5652-5660.

19 X. W. Jimin Xu, C. Shao, D. Su, G. Cheng and Y. Hu, Org. Lett., 2010, 12, 1964-1967.

20 K. Inamoto, K. Nozawa, M. Yonemoto and Y. Kondo, Chem. Commun., 2011, 47, 11775-11777.

21 S. Wertz and A. Studer, Green Chem., 2013, 15, 3116-3134.

22 T. Bach, Angew. Chem., Int. Ed., 2015, 54, 11294-11295.

23 Y. Liu, Y. Song, Y. You, X. Fu, J. Wen and X. Zheng, J. Saudi Chem. Soc., 2018, 22, 439-448.

24 S. Poplata, A. Troster, Y. Q. Zou and T. Bach, Chem. Rev., 2016, 116, 9748-9815.

25 E. R. Shilpa and V. Gayathri, J. Saudi Chem. Soc., 2018, 22, 678-691.

26 R. Alonso and T. Bach, Angew. Chem., Int. Ed., 2014, 53, 43684371.

27 A. M. Asiri, M. S. Al-Amoudi, S. A. Bazaid, A. A. Adam, K. A. Alamry and S. Anandan, J. Saudi Chem. Soc., 2014, 18, 155-163.

28 Y. Zhang, J. Xu and H. Guo, Org. Lett., 2019, 21, 9133-9137. 
29 M. Jiang, H. Yang and H. Fu, Org. Lett., 2016, 18, 5248-5251. 30 I. Kumar, R. Sharma, R. Kumar, R. Kumar and U. Sharma, Adv. Synth. Catal., 2018, 360, 2013-2019.

31 S. P. Pitre, C. D. McTiernan, H. Ismaili and J. C. Scaiano, J. Am. Chem. Soc., 2013, 135, 13286-13289.

32 T. Toyao, N. Ueno, K. Miyahara, Y. Matsui, T. H. Kim, Y. Horiuchi, H. Ikeda and M. Matsuoka, Chem. Commun., 2015, 51, 16103-16106.

33 Y.-T. Xu, C.-Y. Li, X.-B. Huang, W.-X. Gao, Y.-B. Zhou, M.-C. Liu and H.-Y. Wu, Green Chem., 2019, 21, 4971-4975.

34 Y. Q. Zou, J. R. Chen, X. P. Liu, L. Q. Lu, R. L. Davis, K. A. Jorgensen and W. J. Xiao, Angew. Chem., Int. Ed., 2012, 51, 784-788.

35 A. Ding, Y. Chen, G. Wang, Y. Zhang, J. Hu and H. Guo, Polymer, 2019, 174, 101-108.

36 L. Cui, Y. Matusaki, N. Tada, T. Miura, B. Uno and A. Itoh, Adv. Synth. Catal., 2013, 355, 2203-2207.

37 M. Taguchi, Y. Nagasawa, E. Yamaguchi, N. Tada, T. Miura and A. Itoh, Tetrahedron Lett., 2016, 57, 230-232.

38 Q. Zhou, S. Xu and R. Zhang, Tetrahedron Lett., 2019, 60, 734-738.
39 J. M. Carney, R. J. Hammer, M. Hulce, C. M. Lomas and D. Miyashiro, Synthesis, 2012, 44, 2560-2566.

40 D. J. Carlsson, T. Suprunchuk and D. M. Wiles, Can. J. Chem., 1974, 52, 3728-3737.

41 F. Chalier, M. Hardy, O. Ouari, A. Rockenbauer and P. Tordo, J. Org. Chem., 2007, 72, 7886-7892.

42 Y. Liu, L. Wang, Z. Nie, Y. Ji, Y. Liu, K. Liu and Q. Tian, J. Org. Chem., 2006, 71, 7753-7762.

43 S. Kim, Y. Liu, K. M. Nash, J. L. Zweier, A. Rockenbauer and F. A. Villamena, J. Am. Chem. Soc., 2010, 132, 17157-17173.

44 L. Fan, J. Jia, H. Hou, Q. Lefebvre and M. Rueping, Chem.Eur. J., 2016, 22, 16437-16440.

45 L. Huang, X. Cui, B. Therrien and J. Zhao, Chem.-Eur. J., 2013, 19, 17472-17482.

46 J. Luo, X. Zhang and J. Zhang, ACS Catal., 2015, 5, 22502254.

47 I. G. T. M. Penders, Z. Amara, R. Horvath, K. Rossen, M. Poliakoff and M. W. George, RSC Adv., 2015, 5, 65016504.

48 S. D. Sawant, A. D. Hudwekar, K. A. Aravinda Kumar, V. Venkateswarlu, P. P. Singh and R. A. Vishwakarma, Tetrahedron Lett., 2014, 55, 811-814. 